\title{
Carbonates from the lower part of transition zone or even the lower mantle
}

\author{
Frank E. Brenker ${ }^{a, *}$, Christian Vollmer ${ }^{b, 1}$, Laszlo Vincze ${ }^{\mathrm{c}, 2}$, Bart Vekemans ${ }^{\mathrm{d}, 3}$, \\ Anja Szymanski ${ }^{\text {a,4 }}$, Koen Janssens ${ }^{\text {d,5 }}$, Imre Szaloki e,6, Lutz Nasdala ${ }^{\text {f,7, }}$, \\ Werner Joswig $^{\text {a, }}$, Felix Kaminsky ${ }^{\text {g, }} 9$ \\ a Institut für Geowissenschaften, Johann Wolfgang Goethe-Universität Frankfurt, 60054 Frankfurt, Germany \\ ${ }^{\mathrm{b}}$ Max Planck Institute for Chemistry, 55020 Mainz, Germany \\ ${ }^{c}$ Ghent University, Department of Analytical Chemistry, 9000 Ghent, Belgium \\ ${ }^{\mathrm{d}}$ University of Antwerp, Department of Chemistry, 2610 Wilrijk-Antwerp, Belgium \\ ${ }^{\mathrm{e}}$ Institute of Experimental Physics, University of Debrecen, 4026 Debrecen, Hungary \\ ${ }^{\mathrm{f}}$ University of Vienna, Institute of Mineralogy and Crystallography, A-1090 Vienna, Austria \\ ${ }^{g}$ KM Diamond Exploration Ltd., West Vancouver, Canada V7S 3J1
}

Received 19 September 2006; received in revised form 6 February 2007; accepted 25 February 2007

Available online 3 March 2007

Editor: G.D. Price

\begin{abstract}
Effective $\mathrm{CO}_{2}$-storage in the shallow solid Earth mainly occurs by the formation of carbonates. Although the possibility of transport and storage of carbonates to great depth is demonstrated experimentally, ultra-deep mantle carbonates have not been found before. Applying several in situ analytical techniques on inclusions in diamonds from Juina (Brazil) originating from the lower part of the transition zone $(>580 \mathrm{~km})$ or even the lower mantle $(>670 \mathrm{~km})$, reveal the existence of deep Earth carbonates. These finding unquestionably show that at least locally carbonates exist within the deep Earth and may indicate that the Earth's global $\mathrm{CO}_{2}$-cycle has an ultra-deep extension.
\end{abstract} (C) 2007 Elsevier B.V. All rights reserved.

Keywords: Juina; inclusions in diamond; mantle heterogeneity; Raman spectroscopy; X-ray fluorescence

\footnotetext{
(F. Kaminsky).

${ }^{1}$ Tel.: +49 6131 305350; fax: +49 6131305483 .

2 Tel.: +32 9264 4822; fax: +329264 4960 .

${ }^{3}$ Tel.: +32 38202363 ; fax: +32 38202376 .

4 Tel.: +4969798 28721; fax: +496979828066.

${ }^{5}$ Tel.: +32 3820 2373; fax: +32 38202376 .

${ }^{6}$ Tel.: +36 52 4317221529; fax: +36 52315087 .

${ }^{7}$ Tel.: +4314277 53220; fax: +43142779532.

${ }^{8}$ Tel.: +4969798 28794; fax: +4969798 22101 .

${ }^{9}$ Tel.: +1 604925 8755; fax: +1 6049258754 .
}

* Corresponding author. Tel.: +49 69798 28721; fax: +4969798 28066 .

E-mail addresses: f.brenker@em.uni-frankfurt.de (F.E. Brenker), cvollmer@mpch-mainz.mpg.de (C. Vollmer), laszlo.vincze@ugent.be

(L.Vincze), Bart.Vekemans@ua.ac.be (B. Vekemans), aszym@rz.uni-leipzig.de (A. Szymanski), koen.janssens@ua.ac.be (K. Janssens),

szaloki@tigris.klte.hu (I. Szaloki), lutz.nasdala@univie.ac.at (L. Nasdala), Joswig@kristall.uni-frankfurt.de (W. Joswig), felixvkaminsky@cs.com 


\section{Introduction}

Diamonds from the transition zone and the lower mantle have attracted considerable attention in recent years [1-6]. Compared to the majority of diamonds worldwide derived from lithospheric and sub-lithospheric sources, these rare samples provide exceptional insights into the chemistry and dynamics of the deepest accessible parts of the Earth. Several occurrences of such "ultradeep" diamonds have been reported and studied intensively in terms of their chemical characteristics and mineral paragenesis [1-7]. Several aspects, e.g. the Cisotopic composition of the diamond host or Euanomalies of pyroxene (former perovskite) inclusions, link to a subduction-related origin for several of these ultra-deep inclusions $[1,2,6]$.

Although diamonds and their inclusions may probe the deep Earth only locally they are the only direct source of information available and any finding provides information on the physical conditions (pressure, temperature, composition, oxygen fugacity) of their source region. In addition a minimum size of each chemical heterogeneity is expected because temperature is reasonable high in the deep mantle and the timescales of subduction, storage, capture and exhumation exceed tens to hundreds of millions years. Homogenisation is even faster within the transition zone, where the resistance time (time before complete assimilation) of a $\sim 1 \mathrm{~m}$ sized object is calculated to be limited to $\sim 1$ million yrs [8]. Thus, in contrast to crustal or lithospheric environments complete assimilation and homogenisation for small heterogeneities $(<1 \mathrm{~m})$ is expected.

The diamonds investigated in this study were mined from alluvial deposits in the Juina area of south western Brazil. It is shown that these diamonds contain abundant inclusions derived from sources extending from the deep asthenosphere into the lower mantle $[4,5]$.

In the present work, the inclusions were studied in situ (inside the unbroken diamond) by the means of confocal micro X-ray fluorescence [9-11] and micro X-ray diffraction, using synchroton sources at the European Synchroton Radiation Facility (ESRF - Grenoble) and at HasyLab (DESY - Hamburg) and confocal Raman microprobe analyses. These techniques allow the investigation of the chemical composition and structure of even very tiny inclusions $(<5 \mu \mathrm{m})$ with the only sample preparation being the polishing of a window close to the inclusions in the diamond in order to reduce light and $\mathrm{X}$ - ray absorption/scattering effects. Keeping a (reduced) diamond layer covering the inclusions prevents the trapped phases from any contamination and allows better distinction between their syn- and epigenetic origin, which was essential for the present study.

\section{Methods}

\subsection{Micro Raman spectroscopy}

Raman analyses were carried out by means of a Jobin Yvon LabRam HR system (focal length $800 \mathrm{~mm}$ ) equipped with Olympus BX41 optical microscope, a grating with 1800 grooves per $\mathrm{mm}$ in the optical path, and Si-based charge-coupled device detector. Spectra were excited with the $\mathrm{He}-\mathrm{Ne} 632.8 \mathrm{~nm}$ line $(3 \mathrm{~mW}$ at the sample). The wavenumber accuracy was $0.5 \mathrm{~cm}^{-1}$ and the spectral resolution was $0.8 \mathrm{~cm}^{-1}$. The lateral resolution at the actual sampling depth $(100-600 \mu \mathrm{m})$ was on the order of several $\mu \mathrm{m}$ and the depth resolution was probably several tens of $\mu \mathrm{m}$ [9].

\subsection{Confocal X-ray fluorescence imaging}

The confocal X-ray fluorescence (XRF) experiments have been performed at the ID18F microfluorescence end-station of the European Synchrotron Radiation Facility (ESRF). Using one of the most intense X-ray sources available in the world, this instrument allows insitu microscopic multi-element analysis down to $\mathrm{ppm} / \mathrm{ppb}$ concentration levels by K-shell fluorescence in the atomic number range of 19-49. Trace-element analysis of higher-Z elements is possible by their L-lines. Using Compound Refractive Lenses (CRL) as X-ray focusing optics, a lateral resolution level down to $0.4-2 \mu \mathrm{m}$ can be achieved in the vertical dimension, and between 0.8 and $10 \mu \mathrm{m}$ horizontally.

The ID18F X-ray fluorescence microprobe has been primarily tuned for stability and reproducibility, which makes it particularly suitable and successful for quantitative scanning micro XRF applications with high-sensitivity.

In our study, a polycapillary based confocal XRF setup was realized to obtain minor and trace element compositional information in 3 dimensions from diamondinclusions. This is a significant generalization of the conventional scanning XRF technique, which is typically limited to providing 2-D information. The use of polycapillary optics at the detection side allows the local

Fig. 1. Shape, orientation and crystallinity of syngenetic inclusions. (A) Syngenetic calcite and (B) walstromite-structured $\mathrm{CaSiO}_{3}$ inclusions in Juina diamond RS-35. Both inclusions show identical shape and orientation which is diagnostic for their syngenetic origin. (C) The occurrence as calcite single crystal is demonstrated in the SXRD micrograph. 

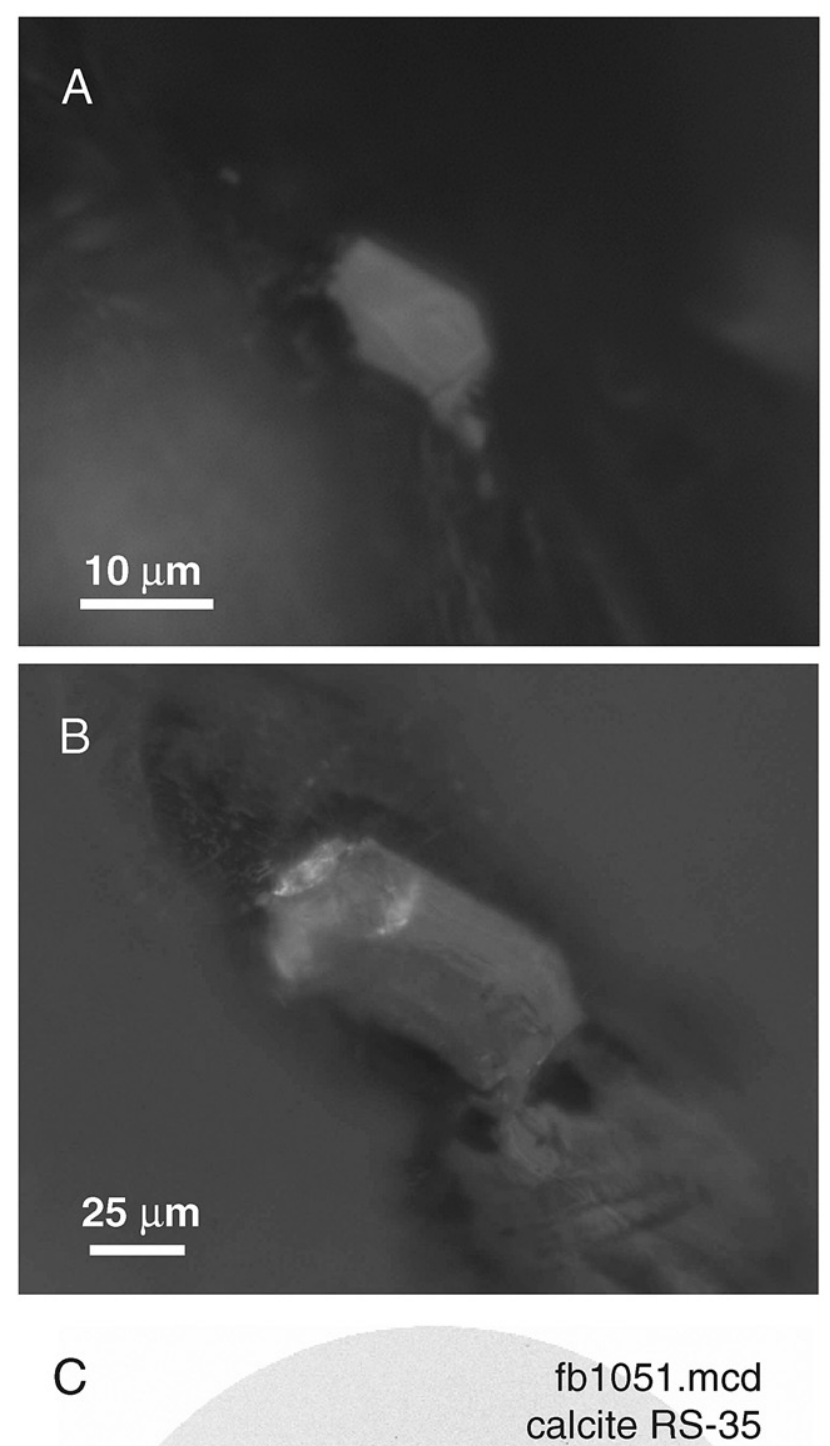

calcite RS-35
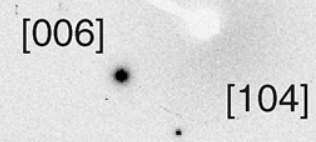


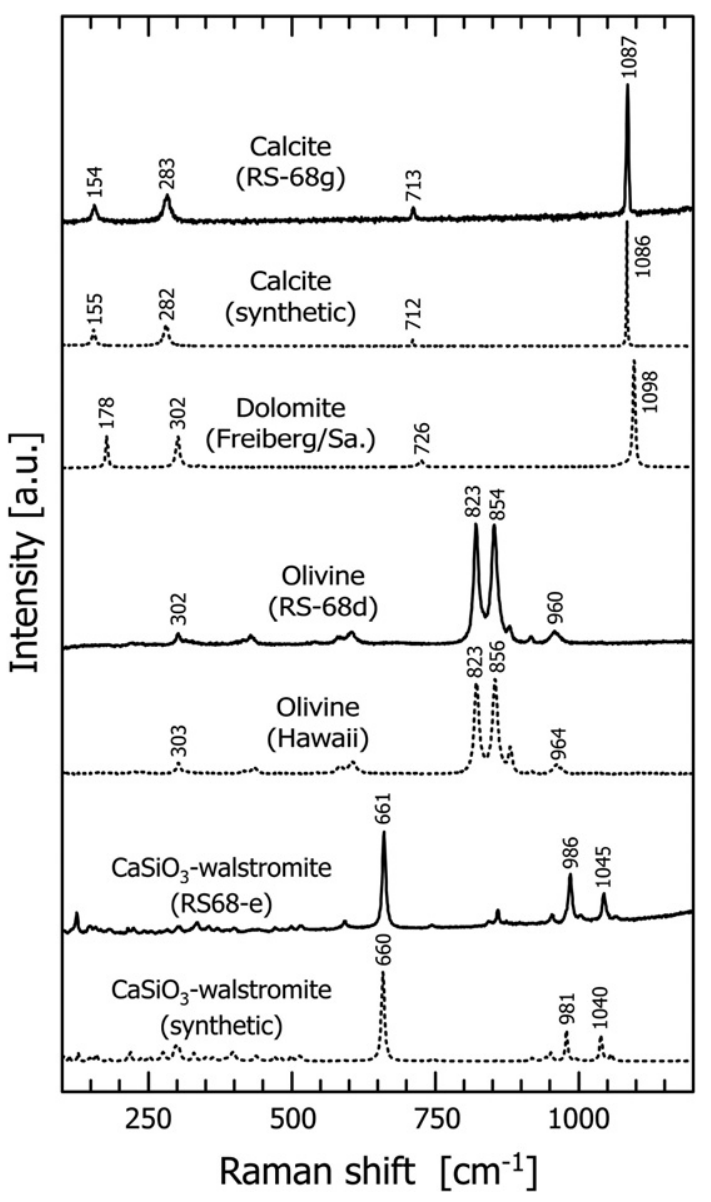

Fig. 2. Typical Raman spectra of minerals included in diamond as obtained in this study (solid lines). Reference spectra (dotted): synthetic calcite [30], natural dolomite (Freiberg, Saxonian Erzgebirge), natural olivine (Kilauea lava flow, Hawaii), and synthetic walstromite [grown by [15]; spectrum described by [11]].

elemental analysis of an arbitrary internal microscopic volume-element, limited only by self-absorption effects, with a volume resolution down to $\sim 5-120 \mu \mathrm{m}^{3}$.

In confocal XRF mode the measured relative detection limits (DLs) vary between 10 and 1 ppm for elements with $\mathrm{Z}>23$ corresponding to a measuring time of $300 \mathrm{~s}$. Considering the typical sampling mass of $0.2-$ $0.3 \mathrm{ng}$, this corresponds to sub-fg absolute DLs for most of the detected trace-elements.

The quantitative evaluation of the measured 3D XRF data-set was performed in two steps. A K-means clustering algorithm was applied first in order to mathematically separate the major phases and calculate their corresponding (average) XRF spectra. This procedure was followed by a fundamental parameter scheme to convert the spectral line intensities into elemental concentrations. The analytical calibration for the above procedure was based on NIST SRM 613 "Trace-elements in Glass" calibration standard.

\section{Results}

\subsection{Phase identification of syngenetic inclusions}

Applying the confocal Raman microprobe technique [12] we identified 69 mineral inclusions within 33 Juina diamonds. Our investigation yielded an unusual suite of "ultra-deep" diamonds, dominated by Ca-rich mineral inclusions. Walstromite-structured $\mathrm{CaSiO}_{3}$ inclusions were identified in 13 cases. Nine of these occurred as single inclusions within five diamonds (No. RS-17, 37, $41,65,66$ ), and only four within two diamonds (No. RS$35,68)$ in association with other minerals. In one case a monomineralic inclusion of larnite $\left(\beta-\mathrm{Ca}_{2} \mathrm{SiO}_{4}\right)$ (No. RS-03) was detected.

The most unexpected finding in these deep mantle diamonds was the detection of several syngenetic carbonate inclusions. The syngenetic nature of the carbonates is demonstrated in detail below. These represent the secondmost frequent inclusion-type found in this suite of ultradeep diamonds. Carbonates were detected in six diamonds (No. RS-05, 30, 35, 59, 63, 68), and in three diamonds (No. RS-35, 59, 68) we found several individual carbonate crystals. The identified carbonates typically have a white colour and are mostly very small, less than $20 \mu \mathrm{m}$ in diameter. The largest crystal found was about $50 \mu \mathrm{m}$.

In two cases an intergrowth of two different carbonate crystals (No. RS-05, RS-59) were identified. The absence of a pressure induced shift of the Raman signal in the surrounding diamond host indicates a low residual pressure within the inclusions and enables the identification of the carbonate phases present. In both cases, the most likely interpretation is a two-phase assemblage of calcite and dolomite.

Two of the diamonds contain isolated inclusions of calcite and walstromite-structured $\mathrm{CaSiO}_{3}$ (Fig. 1) (No. RS-35, RS-68). In diamond RS-68 we even identified three walstromite-structured $\mathrm{CaSiO}_{3}$, two calcite and additionally two olivine inclusions (Figs. 1, 2). The seven inclusions found in diamond RS-68 do not show any systematic trend from core to rim of the diamond, which limits the possibility that all carbonates were captured separately from all other inclusions during a late growth stage of the diamond at lithospheric conditions. These two diamonds are the key samples to reconstruct the formation conditions of this unusual suite of inclusions and therefore the depth of the carbonaceous source region.

The shape of the inclusions in most samples resembles the negative crystal shape of the diamond host, 


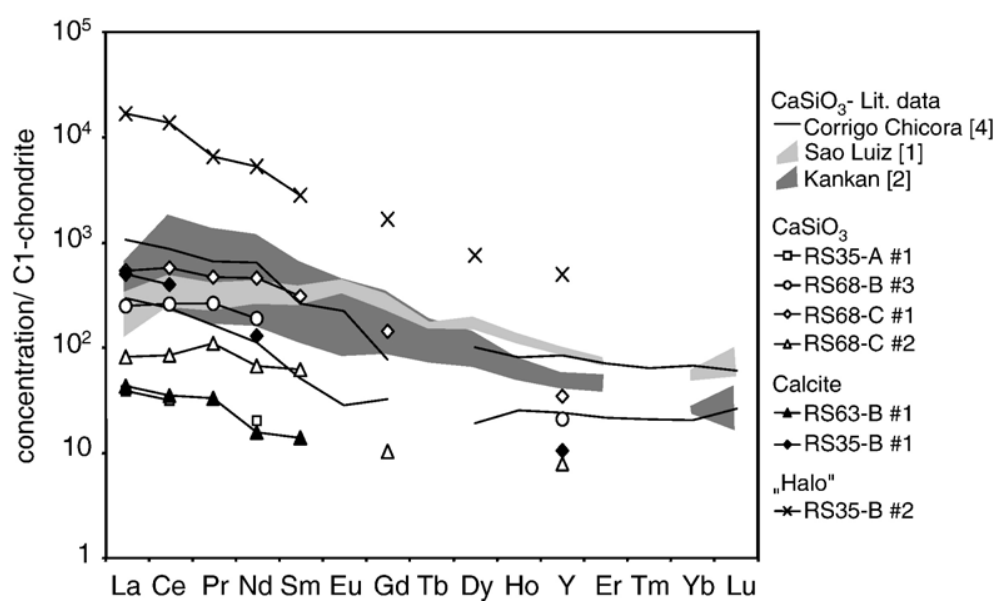

Fig. 3. REE-pattern of Ca-rich inclusions. High-energy synchroton measurement of REE of four walstromite-structured $\mathrm{CaSiO}_{3}$ (open symbols), two calcite (filled symbols) inclusions and a "halo" (crosses) surrounding a calcite inclusion. For comparison published REE-pattern of lower mantle $\mathrm{CaSiO}_{3}$-inclusions found worldwide $[1,2,4]$ is shown.

typically a distorted cube octahedron (Fig. 1). For sample RS-35 this imposition from the diamond host is further confirmed by shifting of the sample in $x$ and $y$ direction from one inclusion to the next and recording their respective shape. It turns out that both inclusions, calcite and walstromite-structured $\mathrm{CaSiO}_{3}$, show identical shape and orientation. A small darker area surrounds the carbonate crystal in sample RS-35. This "halo" around the inclusion is most likely generated by differential volume increase of the inclusion relative to the diamond host during pressure and temperature decrease. This has produced radial fractures in the close surrounding of the inclusion. The diamond lattice, affected by residual strain, partly transforms into graphite [13]. The fractures are very narrow around the inclusion and therefore do not reach the rim of the diamond, thereby preventing contamination or exchange with its surroundings.

X-ray diffraction mapping of individual inclusions demonstrates that all carbonates are single crystals (Fig. 1C) which excludes a pseudomorphic replacement of former syngenetic inclusions by late stage epigenetic carbonates. All late stage carbonates so far identified in diamonds from other locations are typically polycrystalline aggregates with sub-micron grain size and found in surface fractures $[14,15]$. Based on investigations applying cathodoluminescence techniques we can exclude the existence of any open or annealed crack leading from the surface of the diamond to the inclusions.

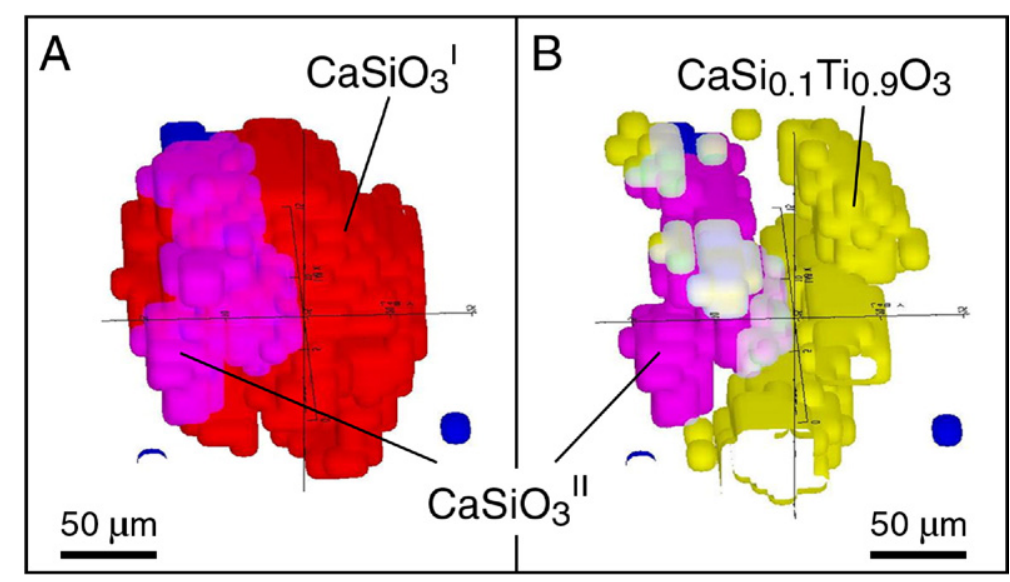

Fig. 4. Tomographic view of polyphase inclusion RS-68c. (A) Clustering showing the distribution of the $\mathrm{CaSiO}_{3}$ phase (red and purple) and in (B) the $\mathrm{Zr}$-rich region only $\left(\mathrm{CaSiO}_{3}^{\mathrm{II}}\right.$, purple), within the total volume of the CaTi-perovskite (yellow). 
Table 1

X-ray diffraction of Ca,Ti-perovskite

\begin{tabular}{|c|c|c|c|c|c|c|}
\hline & \multirow{2}{*}{\multicolumn{2}{|c|}{ Sample No. RS-68c }} & \multicolumn{4}{|l|}{ Perovskite Pbnm } \\
\hline & & & \multicolumn{2}{|l|}{$\mathrm{CaTi}_{0.85} \mathrm{Si}_{0.15} \mathrm{O}_{3}$} & \multicolumn{2}{|l|}{$\mathrm{CaTi}_{0.95} \mathrm{Si}_{0.05} \mathrm{O}_{3}$} \\
\hline$a_{0}[\AA]$ & & & 5.351 & & 5.384 & \\
\hline$b_{0}[\AA]$ & & & 5.375 & & 5.437 & \\
\hline$c_{0}[\AA]$ & & & 7.574 & & 7.637 & \\
\hline hkl & $d$-value $[\AA]$ & Relative intensity & $d$-value $[\AA]$ calculated & Relative intensity & $d$-value $[\AA]$ calculated & Relative intensity \\
\hline 002 & 3.80 & 16 & 3.79 & 28 & 3.82 & 21 \\
\hline 111 & & & 3.39 & 45 & 3.42 & 39 \\
\hline 020 & 2.63 & 33 & 2.69 & 88 & 2.72 & 88 \\
\hline 200 & & & 2.68 & 81 & 2.69 & 82 \\
\hline 013 & & & 2.29 & 11 & 2.21 & 44 \\
\hline 211 & & & 2.28 & 37 & 2.20 & 40 \\
\hline 022 & 2.19 & 8 & 2.19 & 48 & & \\
\hline 202 & & & 2.19 & 43 & & \\
\hline 220 & 1.90 & 100 & 1.90 & 100 & 1.91 & 100 \\
\hline 004 & & & 1.89 & 60 & 1,91 & 66 \\
\hline 031 & & & 1.74 & 11 & & \\
\hline 213 & & & 1.74 & 14 & & \\
\hline 024 & 1.55 & 11 & 1.55 & 32 & 1.56 & 30 \\
\hline 204 & & & 1.55 & 31 & 1.56 & 30 \\
\hline 040 & 1.35 & 2 & 1.34 & 10 & & \\
\hline 224 & 1.32 & 1 & 1.34 & 47 & 1.35 & 38 \\
\hline
\end{tabular}

Note: The comparison of measured vs. calculated $d$-values and respective intensities of Si-bearing CaTi-perovskite based on published lattice parameters [30] yield a best fit assuming a Ti/Si ratio of 0.1 , which is similar to recent findings of coexisting CaTi-perovskite with walstromite-structured $\mathrm{CaSiO}_{3}$ [5].

\subsection{Composition and three-dimensional chemical and structural variation}

To further confirm the genetic link between the included carbonates and the coexisting walstromitestructured $\mathrm{CaSiO}_{3}$ and to compare our findings with other lower mantle $\mathrm{Ca}$-silicates found worldwide we performed in situ high-energy synchrotron radiation micro X-ray fluorescence and micro X-ray diffraction experiments. Applying these in situ techniques it was possible to quantify the rare earth element (REE) contents of several of the included $\mathrm{CaSiO}_{3}$ phases, two carbonates, and, in one case, the surrounding dark "halo" (Fig. 3).

All measured phases display similar types of REEpattern. The obtained patterns show strong enrichment of LREE decreasing gradually towards heavier REE, which is similar to published REE contents of lower mantle $\mathrm{CaSiO}_{3}$ phases found worldwide (Sao Luiz, Kankan, Corrigo Chicora) $[1,2,4]$ (Fig. 3). The mean enrichment is around 100 times $\mathrm{C} 1$ chondrite [16]. The halo yields the highest REE content, of up to 10,000 times chondritic followed by walstromite-structured $\mathrm{CaSiO}_{3}$ inclusions and the carbonates. Calcite and walstromite-structured $\mathrm{CaSiO}_{3}$ phases coexisting within the same diamond yield nearly identical REE-pattern, with calcite showing higher values. Absorption of the diamond host prevents the in situ detection of REE at lower concentration levels. Thus, the genetic fingerprint remains incomplete.
Two walstromite-structured $\mathrm{CaSiO}_{3}$ inclusions were studied in greater detail using newly established confocal micro XRF tomographic techniques [9-11], combined

Table 2

Quantitative X-ray fluorescence data of inclusion RS-68c

\begin{tabular}{lllll}
\hline Element & $\begin{array}{l}\mathrm{CaSiO}_{3}^{\mathrm{I}} \\
\text { (red) }\end{array}$ & $\begin{array}{l}\mathrm{CaTi}_{0.9} \mathrm{Si}_{0.1} \mathrm{O}_{3} \\
\text { (yellow) }\end{array}$ & $\begin{array}{l}\mathrm{CaSiO}_{3}^{\mathrm{II}} \\
\text { (purple) }\end{array}$ & $\begin{array}{l}\mathrm{Zr}, \mathrm{Hf}, \text { Th-rich } \\
\text { (blue) }\end{array}$ \\
\hline $\mathrm{K}$ & $<\mathrm{DL}$ & $109 \pm 40$ & $770 \pm 250$ & $<\mathrm{DL}$ \\
$\mathrm{Ca}$ & $34 \pm 8 \%$ & $24 \pm 6 \%$ & $37 \pm 9 \%$ & $20 \pm 5 \%$ \\
$\mathrm{Ti}$ & $0.12 \pm 2 \%$ & $28 \pm 5 \%$ & $0.25 \pm 0.04 \%$ & $0.6 \pm 0.1 \%$ \\
$\mathrm{~V}$ & $102 \pm 12$ & $1.1 \pm 0.2 \%$ & $246 \pm 30$ & $620 \pm 70$ \\
$\mathrm{Cr}$ & $47 \pm 5$ & $1450 \pm 150$ & $12 \pm 2$ & $584 \pm 58$ \\
$\mathrm{Mn}$ & $135 \pm 11$ & $286 \pm 30$ & $50 \pm 5$ & $77 \pm 6$ \\
$\mathrm{Fe}$ & $424 \pm 30$ & $790 \pm 60$ & $231 \pm 17$ & $343 \pm 23$ \\
$\mathrm{Co}$ & $6 \pm 1$ & $9 \pm 1$ & $4 \pm 1$ & $<\mathrm{DL}$ \\
$\mathrm{Ni}$ & $<\mathrm{DL}$ & $2 \pm 1$ & $<\mathrm{DL}$ & $1 \pm 1$ \\
$\mathrm{Sr}$ & $266 \pm 11$ & $158 \pm 4$ & $279 \pm 6$ & $224 \pm 5$ \\
$\mathrm{Y}$ & $28 \pm 1$ & $32 \pm 1$ & $56 \pm 2$ & $83 \pm 2$ \\
$\mathrm{Zr}$ & $269 \pm 8$ & $365 \pm 8$ & $1400 \pm 30$ & $2.3 \pm 0.1 \%$ \\
$\mathrm{Nb}$ & $<\mathrm{DL}$ & $<\mathrm{DL}$ & $<\mathrm{DL}$ & $9 \pm 2$ \\
$\mathrm{Nd}$ & $10 \pm 1$ & $1940 \pm 44$ & $<\mathrm{DL}$ & $<\mathrm{DL}$ \\
$\mathrm{Gd}$ & $29 \pm 1$ & $319 \pm 8$ & $15 \pm 1$ & $17 \pm 1$ \\
$\mathrm{Hf}$ & $24 \pm 1$ & $68 \pm 2$ & $124 \pm 3$ & $2550 \pm 50$ \\
$\mathrm{Th}$ & $<\mathrm{DL}$ & $<\mathrm{DL}$ & $<\mathrm{DL}$ & $10 \pm 1$ \\
$\mathrm{U}$ & $1 \pm 1$ & $<\mathrm{DL}$ & $2 \pm 1$ & $6 \pm 1$ \\
\hline
\end{tabular}

Note: The evaluation of the measured 3D XRF data-set of four different clusters (pink, red, yellow and blue cluster) shown in Fig. 4 based their corresponding (average) XRF spectra. All data are given in $\mathrm{ppm}$ if not indicated as percentage concentration level. The respective errors are given for each calculation. 
with micro XRD mapping. Sample RS-37a shows a rather homogeneous distribution of all elements indicating a pure $\mathrm{CaSiO}_{3}$ inclusion. In the case of RS-68c a complex intergrowth of at least two Ca-rich phases was found. The clustering of the three-dimensional dataset yield well separated regions of a $\mathrm{Ca}$, Ti-rich and a Ca-rich but Ti-poor phase (Fig. 4). Within the Ti-poor phase a region showing slightly enriched $\mathrm{Zr}$ and Y-values was found (Fig. 4A). The quantitative evaluation of the correspondent $\mathrm{X}$-ray fluorescence spectra (Table 1) reveal $\mathrm{CaTiO}_{3}, \mathrm{CaSiO}_{3}$ (I) and $\mathrm{Zr}, \mathrm{Y}$ enriched $\mathrm{CaSiO}_{3}$ (II) as coexisting phases.

The XRD map of this inclusion displays a similar distribution of the Ti-rich region compared with a reflection having a $d$-value of $3.8 \AA$. Additional reflections found in this region (Table 2) suggest Si-bearing CaTiperovskite with $\mathrm{Si} / \mathrm{Ti}$ ratios around 0.1 (Fig. 4), similar to recent findings of CaTi-perovskite from the same region [5]. The XRD-values found in the remaining part of the inclusion indicate walstromite-structured $\mathrm{CaSiO}_{3}$ as the main phase, which is in accordance with the measured Raman spectra of this inclusion.

Thus, inclusion RS-68c is mainly composed of walstromite-structured $\mathrm{CaSiO}_{3}$ and $\mathrm{CaTiO}_{3}$-perovskite, with walstromite-structured $\mathrm{CaSiO}_{3}$ showing an Y,Zrenriched central part.

The XRD measurements of the olivine inclusions in sample Rs-68 reveal single crystals without evidence of small scale spinell exsolutions.

\section{Discussion}

\subsection{Source depth of the carbonate inclusions}

The occurrence of Ca-silicates as inclusions in diamonds is commonly explained by entrapment of CaSi-perovskite $[2,5]$, the only expected pure $\mathrm{Ca}-\mathrm{Si}-\mathrm{O}$ phase stable in the Earth's mantle [17]. For peridotitic source compositions this mineral phase can form in the lower part of the transition zone (>580 km depth), together with ringwoodite ( $\gamma$-olivine) and majorite, and in the lower mantle (>670 km depth), together with $\mathrm{MgSi}$-perovskite and $\mathrm{MgO}$. In eclogitic source compositions (e.g. related to subducted oceanic crust), CaSiperovskite will start to form in the lower part of the transition zone ( $>580 \mathrm{~km}$ depth) as well, but coexisting with stishovite $\left(\mathrm{SiO}_{2}\right)$ and majorite [17]. Even if we assume sediments as precursor material, a pure CaSiperovskite is stable in the Earth's mantle only at depths exceeding $580 \mathrm{~km} \mathrm{[16].}$

Pure $\mathrm{Ca}-\mathrm{Si}-\mathrm{O}$ phases can only be found in the Earth's mantle above $580 \mathrm{~km}$, in unusual circumstances, for example if we are dealing with specific lithologies, like marble or carbonatite. This has been documented in a single case from Kankan [8]. However, we can exclude this possibility in the present case, because of the occurrence of Mg-rich inclusions (e.g. olivine in RS68) coexisting with the $\mathrm{CaSiO}_{3}$, within the same diamond. In the upper mantle at depths above $580 \mathrm{~km}$ this assemblage would lead to the formation of majorite or clinopyroxene instead. Thus, only two explanations for the observed assemblage olivine + walstromite-structured $\mathrm{CaSiO}_{3}$ remain. Either the precursor paragenesis was ringwoodite $\left(\gamma-\mathrm{Mg}_{2} \mathrm{SiO}_{4}\right)+\mathrm{CaSi}$-perovskite, that are stable only within the lowermost part of the transition zone (580-670 km depth), or the lower mantle assemblage of periclase $(\mathrm{MgO})+\mathrm{MgSi}$-perovskite + CaSi-perovskite (>670 km depth). During ascent several retrograde phase-transformations would have occurred [18]. Olivine is formed from its high-pressure modification ringwoodite or as a retrograde reaction product of $\mathrm{MgO}$ and $\mathrm{MgSi}$-perovskite. No evidence for small scale spinell exsolutions occurring in similar super deep olivine inclusions [7] was found. The olivine crystals are monocrystalline indicating initial slow ascent.

The finding of walstromite-structured $\mathrm{CaSiO}_{3}$ together with $\mathrm{CaTiO}_{3}$-perovskite within the same inclusion further confirms the ultra-deep origin of the inclusion suite. Similar two phase assemblages were found in two other cases of inclusions in diamonds from the same area [5]. This phase assemblage is interpreted as a former $\mathrm{CaSi}_{1-x} \mathrm{Ti}_{x} \mathrm{O}_{3}$-perovskite solid solution, requiring a minimum pressure of approx. 9.5 $\mathrm{GPa}[19]$.

\subsection{Genetic relation between carbonate and walstro- mite-structured $\mathrm{CaSiO}_{3}$}

The observed imposition of the dominant crystallographic faces of the diamond on the inclusions (Fig. 1) strongly supports a syngenetic or protogenetic origin [20]. The occurrence of carbonates as single crystals negates the possibility of the calcite being a secondary, epigenetic alteration product or crystallized from a trapped carbonatitic melt [21]. Epigenetic alteration products in diamond are typically found along cracks, do not show a cube octahedral shape and are always polycrystalline aggregates of sub-micron sized crystals. Minerals crystallizing from a melt evolve their own unique crystal habit in accordance to their crystal structure.

Episodic growth of diamonds is a well known phenomenon. However, it is unlikely that all carbonate inclusions found in this unusual suite of ultra-deep diamonds are trapped during a late stage lithospheric event, whereas all other inclusions represent deep mantle material. 
The similarities of LREE-pattern of calcite and walstromite-structured $\mathrm{CaSiO}_{3}$ found within the same diamond and compared with lower mantle $\mathrm{CaSiO}_{3}$ inclusions found worldwide may indicate that the source of all inclusion suites are genetically linked and represent identical source materials.

Thus, the coexistence of a walstromite-structured $\mathrm{CaSiO}_{3}$ and olivine with syngenetic calcite (No. RS-68) within the same diamond, together with the finding of a two phase assemblage of walstromite-structured $\mathrm{CaSiO}_{3}$ and $\mathrm{CaTiO}_{3}$-perovskite, leads to the well founded assumption that the carbonate was incorporated into the diamond in the lower part of the transition zone (>580 km depth) or even the lower mantle.

\subsection{Origin of the carbonate reservoir}

The origin of these deep mantle carbonates is most likely related to $\mathrm{CO}_{2}$-enriched crustal or lithospheric material that has been transported to great depths via subduction processes, associated with destructive plate margins. Carbonate in subducting slabs comprises several lithologies: if the basaltic oceanic crust is altered and metasomatically $\mathrm{Ca}$-enriched, rodingite is formed. $\mathrm{Ca}$ metasomatism of peridotitic lithospheric mantle, on the other hand, leads to the formation of a specific rock type called ophicarbonates [22]. Compacted, dense biogenic calcareous $\left(\mathrm{CaCO}_{3}\right.$-rich $)$ and siliceous $\left(\mathrm{SiO}_{2}\right.$-rich $)$ ooze horizons, on top of the basaltic crust can also become subducted, whereas the majority of clastic terrigeneous sediments are sheared off the slab in the accretion wedge [23]. The presence of olivine + walstromite-structured $\mathrm{CaSiO}_{3}+$ calcite found in this work favours ophicarbonate as precursor lithology.

High-pressure phase equilibria calculated for ophicarbonates suggest that the original carbonate is retained during subduction of the oceanic lithospheric slab to depths exceeding $200 \mathrm{~km}$ [24]. High-pressure experiments also show that melting of such carbonate-bearing basaltic or peridotitic material is impeded in deep, cold regions of the subducted lithosphere, to depths of the transition zone [24]. Furthermore, decarbonation of aragonite is an experimentally well known mechanism for diamond formation at conditions of the lower part of the upper mantle $[25,26]$. Findings of carbonates in diamonds of shallower origin [27] and experiments in the MORB- $\mathrm{CaCO}_{3}$ system [28] support the possible connection between subducted calcareous material and the formation of diamond.

It was further established that the carbon solubility in normal mantle minerals like olivine or pyroxene [29] is very low, so that there is a need for the existence of another carbon-bearing phase in the mantle, most likely in the form of carbonate [29].

We have not only found direct proof for the existence of this important carbon phase, but herein documented its extension to depths exceeding the lower part of the transition zone, which may indicate that the global $\mathrm{CO}_{2-}$ cycle has an ultra-deep extension.

\section{Acknowledgements}

We like to thank the ESRF (beamline ID18F) and the HASYLab (beamline L) for providing the beamtime and Remi Tucoulou Tachoueres, Sylvain Bohic and Gema Martinez Criado for the support during the measurements at the ESRF. This work was supported by the Deutsche Forschungsgemeinschaft (DFG, Grant Br 2015/9-1).

\section{References}

[1] B. Harte, J.W. Harris, M.T. Hutchison, G.R. Watt, M.C. Wilding, Lower mantle mineral associations in diamonds from Sao Luiz, Brazil, in: Y. Fei, C.M. Bertka, B.O. Mysen (Eds.), Mantle Petrology: Field Observations and High Pressure Experimentation: A tribute to Francis R. (Joe) Boyd, vol. 6, Geochemical Society, USA, 1999, pp. 125-153.

[2] T. Stachel, J.W. Harris, G.P. Brey, W. Joswig, Kankan diamonds (Guinea) II: lower mantle inclusion parageneses, Contrib. Mineral. Petrol. 140 (2000) 16-27.

[3] T. Stachel, Diamonds from the asthenosphere and the transition zone, Eur. J. Mineral. 13 (2001) 883-892.

[4] F. Kaminsky, O.D. Zakharchenko, R. Davies, W.L. Griffin, G.K. Khachattryan-Blinova, A.A. Shiryaev, Superdeep diamonds from the Juina area, Mato Grosso State, Brazil, Contrib. Mineral. Petrol. 140 (2001) 734-753.

[5] P. Hayman, M. Kopylova, F. Kaminsky, Lower mantle diamonds from Rio Soriso (Juina area, Mato Grosso, Brazil), Contrib. Mineral. Petrol. 149 (2005) 430-445.

[6] R. Tappert, T. Stachel, J.W. Harris, K. Muehlenbachs, T. Ludwig, G.P. Brey, Subducting oceanic crust: the source of deep diamonds, Geology 33 (2005) 565-568.

[7] F.E. Brenker, T. Stachel, J.W. Harris, Exhumation of lower mantle inclusions in diamond - ATEM investigation of retrograde phase transitions, reactions and exsolution, Earth Planet. Sci. Lett. 198 (2002) 1-9.

[8] S. Chakraborty, R. Knoche, H. Schulze, D.C. Rubie, D. Dobson, N.L. Ross, R.J. Angel, Enhancement of cation diffusion rates across the 410-kilometer discontinuity in Earth's mantle, Science 283 (1999) 362-365

[9] F.E. Brenker, L. Vincze, B. Vekemans, L. Nasdala, T. Stachel, C. Vollmer, M. Kersten, A. Somogyi, F. Adams, W. Joswig, J.W Harris, Detection of a Ca-rich lithology in the Earth's deep $(>300 \mathrm{~km})$ convecting mantle, Earth Planet. Sci. Lett. 236 (2005) 579-587.

[10] L. Vincze, B. Vekemans, F.E. Brenker, G. Falkenberg, K. Rickers, A. Somogyi, M. Kersten, F. Adams, Three-dimensional trace element analysis by confocal X-ray microfluorescence imaging, Anal. Chem. 76 (2004) 6786-6791. 
[11] B. Vekemans, L. Vincze, F.E. Brenker, F. Adams, Processing of three-dimensional microscopic X-ray fluorescence data, J. Anal. At. Spectrom. 19 (2004) 1302-1308.

[12] L. Nasdala, F.E. Brenker, J. Glinnemann, W. Hofmeister, T. Gasparik, J.W. Harris, T. Stachel, I. Reese, Spectroscopic 2Dtomography: residual pressure and strain around mineral inclusions in diamonds, Eur. J. Mineral. 15 (2003) 931-935.

[13] L.A. Taylor, M. Anand, P. Promprated, L.A. Taylor, M. Anand, P. Promprated, Diamonds and their Inclusions: Are the Criteria for Syngenesis Valid? 8th Int. Kimberlite Conf. Victoria, Canada, 2003, (ext. abstr.).

[14] J.W. Harris, The recognition of diamond inclusions, Industrial Diamond Review 28 (1968) (Part I, 402-410 and Part II, 458-461).

[15] J.W. Harris, pers. communication (2006).

[16] H. Palme, A. Jones, Solar system abundances of the elements, in: A.M. Davis (Ed.), Meteorites, Comets, and Planets, Treatise on Geochemisty, vol. 1, 2003, pp. 41-62.

[17] T. Irifune, A.E. Ringwood, W.O. Hibberson, Subduction of continental-crust and terrigenous and pelagic sediments - an experimental-study, Earth Planet. Sci. Lett. 126 (1994) 351.

[18] W. Joswig, T. Stachel, J.W. Harris, W.H. Baur, G.P. Brey, New Ca-silicate inclusions in diamonds - tracers from the lower mantle, Earth Planet. Sci. Lett. 173 (1999) 1-6.

[19] T. Kubo, T. Suzuki, M. Akaogi, High pressure phase equilibria in the system $\mathrm{CaTiO}_{3}-\mathrm{CaSiO}_{3}$ : stability of perovskite solid solutions, Phys. Chem. Miner. 24 (1997) 488-494.

[20] J.W. Harris, in: J.E. Field (Ed.), The Properties of Diamond, Academic Press, London, 1979, pp. 555-591.
[21] O. Klein-Ben David, R. Wirth, O. Navon, TEM imaging and analysis of microinclusions in diamonds: a close look at diamondgrowing fluids, Am. Mineral. 91 (2006) 353-365.

[22] E. Bonatti, J.R. Lawrence, P.R. Hamlyn, D. Breger, Aragonite from deep sea ultramafic rocks, Geochim. Cosmochim. Acta 44 (1980) 1207-1214.

[23] J.C. Moore, Selective subduction, Geology 3 (1975) 530-532.

[24] D.M. Kerrick, J.A.D. Connolly, Subduction of ophicarbonates and recycling of $\mathrm{CO}_{2}$ and $\mathrm{H}_{2} \mathrm{O}$, Geology 26 (1998) 375-378.

[25] Y.N. Pal'yanov, A.G. Sokol, Y.M. Borzdov, A.F. Khokhryakov, N.V. Sobolev, Diamond formation through carbonate-silicate interaction, Am. Mineral. 87 (2002) 1009-1013.

[26] L.-G. Liu, An alternative interpretation of lower mantle mineral associations in diamonds, Contrib. Mineral. Petrol. 144 (2002) $16-21$.

[27] M. Schrauder, O. Navon, Hydrous and carbonatitic mantle fluids in fibrous diamonds from Jwaneng, Botswana, Geochim. Cosmochim. Acta 58 (1994) 761-771.

[28] M. Arima, Y. Kozai, M. Akaishi, Diamond nucleation and growth by reduction of carbonate melts under high-pressure and high-temperature conditions, Geology 30 (2002) 691-694.

[29] H. Keppler, M. Wiedenbach, S.S. Scheka, Carbon solubility in olivine and the mode of carbon storage in the Earth's mantle, Nature 424 (2003) 414-416.

[30] K. Leinenweber, A. Grzechnik, M. Voorhees, A. Navrotsky, A. Yao, P.F. McMillan, Structural variation in $\mathrm{Ca}\left(\mathrm{Ti}_{x} \mathrm{Si}_{1-x}\right) \mathrm{O}_{3}$ perovskites $(1>x>0.65)$ and the ordered phase $\mathrm{Ca}_{2} \mathrm{TiSiO}_{6}$, Phys. Chem. Miner. 24 (1997) 528-534. 